\title{
CONVECTION HEAT TRANSFER AND PRESSURE DROP FOR DILUTE POLYMER SOLUTIONS FLOW INSIDE MULTI- CHANNELS H'LA'T TUBE
}

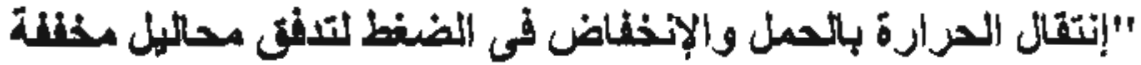

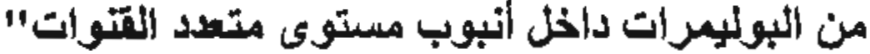 \\ Hesham M. Mostafa and Tarek F. Oda \\ Mechanical Eng. Dept., Higher Technological Institute, Tenth of Ramadan City, Egypt. \\ Email: DrHeshamMostafa@Yahoo.com\&Tarekrok@Yahoo.com
}

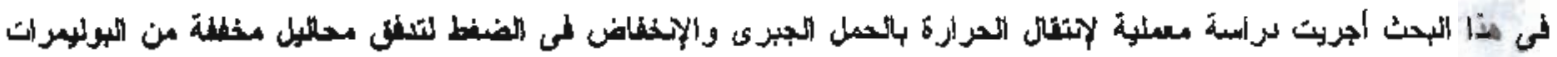

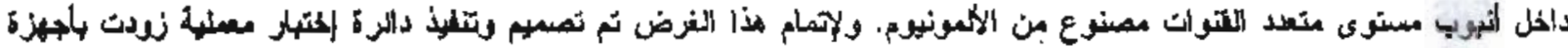

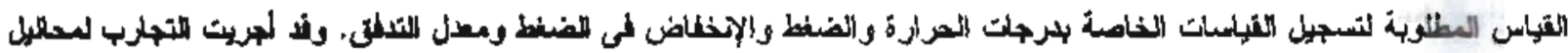

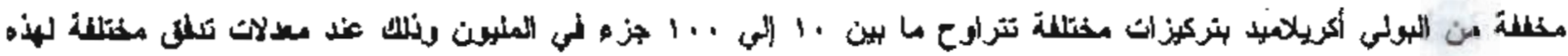

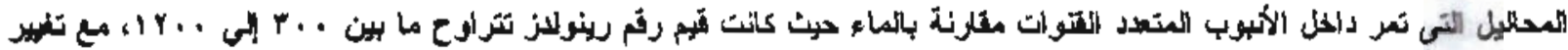

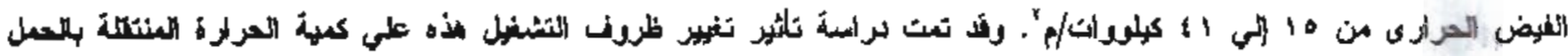

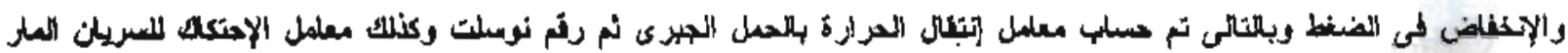

دأخل الألبيوب العتعد التثوات.

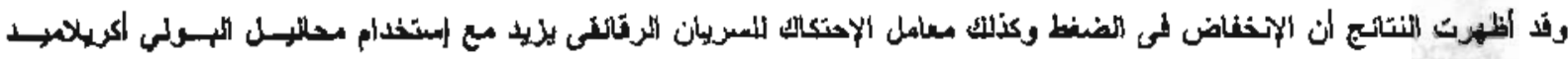

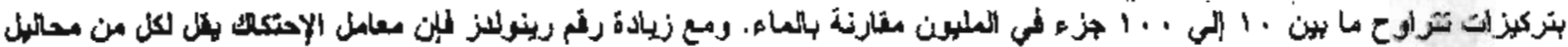

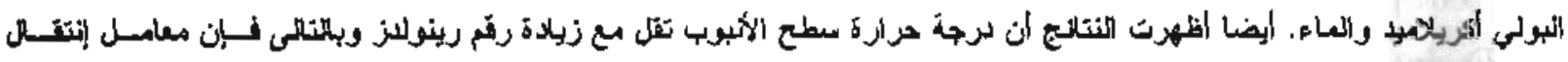

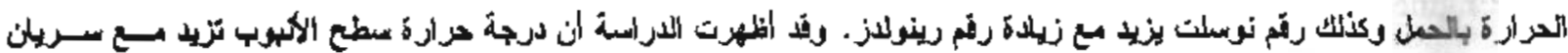

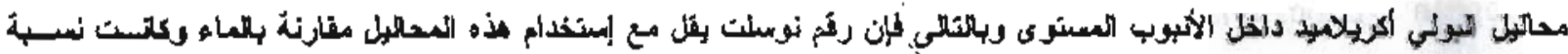

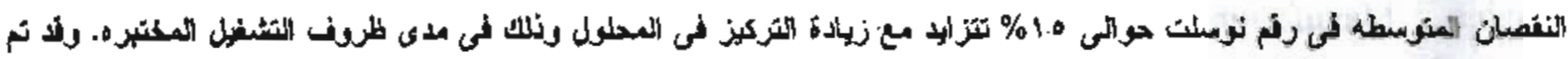

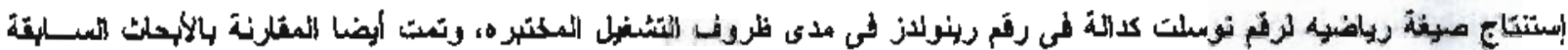

حبث اعطت لنس الإجهاه.

\section{ABSTRACT}

Convection heat transfer and pressure drop is investigated experimentally, for the flow of dilute polymer solutions (polyacrylamide) inside multi-channels flat tube and compared with water. An experimental apparatus equipped with the required measuring devices is designed and constructed to assess the effects of the operating parameters on convection heat transfer and pressure drop. The flat Aluminum multi-channels extruded tube composed of 22 parallel rectangular mini-channels (3.6 $\mathrm{mm} \times 3.85 \mathrm{~mm}$ ) with hydraulic diameter of $3.72 \mathrm{~mm}$. Different polymer concentrations are considered; 10, 20, 50 and $100 \mathrm{ppm}$. This work covers a range of Reynolds number from 300 to 
1200 and heat flux from 15 to $4 ! \mathrm{kW} / \mathrm{m}^{2}$. The experimental measurements for flow rate, temperature, pressure, and pressure drop are taken to perform the required analysis. Therefore, the average value of convection heat transfer coefficient and friction factor for different operating parameters are computed.

The obtained experimental results show that, the laminar-turbulent transition occurs in the rarige of $R \mathrm{R}=1100-2000$. Pressure drop and in turn friction factor takes higher values for laminar flow of polymer solutions compared with water. Friction factor decreases with increasing Reynolds number for both polymer soluticns and water flow inside the flat tube. Surface temperature of flat tube decreases with increasing Reynolds number for both polymer solutions and water. Accordingly, convection heat transfer coefficient and in tum Nusselt number are increased. When using polymer solutions, the surface temperature of flat tube increases compared with water. Therefore, Nusselt number is decreased. The reduction value in Nu increases with increasing concentration of polymer solution. The average value for this reduction in $\mathrm{Nu}$ was about $15 \%$. An empirical correlation for Nusselt number is obtained in the range of the studied operating parameters. Comparison between the obtained experimental results with the previous data is done and gives the same trend.

Key words: Mini-channels, Flat fube, Convection heat transfer, Polymer solutions

\section{INTRODUCTION}

The developments of new applications were in need of cooling for components in a confined space. Recent studies have been motivated in order to predict the fluid flow and heat transfer in mini- and micro-channels. The studying of hydrodynamic and heat transfer in mini- and micro- channels was helpful in several engineering systems. Aluminum brazed heat exchangers are used widely in automobile air conditioning systems. Usually, this kind of heat exchanger is made of a flat tube with several independent passages in the cross-section, and formed into serpentine or parallel flow geometry.

The classification of micro - mini channels according to their dimension was proposed by Mehendale et al. [1], Kandlikar and Grande [2]. Both classifications are defined over the value of the smaller dimension of the channels. Mehendale et al. [1] reviewed the flow and heat transfer in small channels with hydraulic diameters ranging from $1 \mu \mathrm{m}$ to $6 \mathrm{~mm}$ and adopt the following classifications:

Micro-heat exchanger: $\mathrm{D}_{1 \mathrm{n}}=1-100 \mu \mathrm{m}$; Meso-heat exchangers: $D_{h}=100 \mu \mathrm{m}-1 \mathrm{~mm}$; Compact heat exchangers: $D_{h}=1-6 m m$; Conventional heat exchangers: $D_{k}>6 \mathrm{~mm}$.

Bavie te et a]. [3] investigated water circulation in a single flat channel made of Pyrex. Their measurements give a value of 96 for the Poiseuille number which was very close to the predictions by Shah and London [4].

Gao et al. [5] investigated water circulation in a channel having a hydraulic diameter ranging from 200 to $1923 \mu \mathrm{m}$, and also oblained a good agreement between their results and those of conventional channels. The friction measurements by Gao et al. [5] as a function of the Reynolds number for different hydraulic diameters were in good agreement by Shah and London [4] correlations for laminar and turbulent regimes, respectively. Gao et al. [5] reported that, the values of the Nusselt number lower than the values obtained from theoretical conventional correlations for both laminar and turbulènt regimes.

Drag reduction is a field of study in many engineering disciplines, such as mechanical, aeronautical, aerospace, marine technology, automobile ...etc. The addition of a few parts per million of polymer to the solvent reduced the pressure drop substantially below that of the solvent alone at the same flow rate only when the flow was turbulent. Rheological studjes of these fluids confirmed that they have nonNewtonian, viscoelastic behavior even at very dilute solutions. The reduction in frictional drag of turbulent pipe flow of such viscoelastic fluids was found to be associated with similar 
reduction in heat and mass transfer, Rabie et al. $[6,7]$.

Many experimental studies have been carried out to study heat transfer and fluid flow of drag reducing polymer flow, (Rabie et al. [7], Kawack et al. [8], Deberule et al. [9]). Most of these studies were carried out at turbulent flow conditions to get the benefit of the enormons frictional drag reductions. A large reduction in heat transfer as well as frictional drag is found.

Rosa et al. [10] presents a review of the experimental and numerical results available in the open literature for single phase in microchannels. They found that, inconsistencies between published results still exist and there is no generally accepted model for the prediction of single phase heat transfer in micro-channels.

Experimental work was performed by Naphon and khonseur [11] to investigate the heat transfer characteristics and pressure drop in the microchannel heat sinks under constant heat flux conditions. Two different channel height and two different channel widths were studied. The micro-channel geometry configuration had significant effect on heat transfer and pressure drop.

Agostini et al. [12] presented friction factor and heat transfer coefficient experimental results obtained with a liquid flow of R134a in rectangular mini-channels. Two test sections made of Aluminum multi-port extruded (MPE) tubes (charnels dimensions $1.11 \mathrm{~mm} \times 1.22 \mathrm{~mm}$ and $0.73 \mathrm{~mm} \times 0.72 \mathrm{~mm}$ ) were tested. The laminar-turbulent transition occured around $\mathrm{Re}=2000$.

Peng and Peterson [13] studied experimentally the forced convection heat transfer and flow characteristics of water flowing through meso-channel plates with extremely small rectangular channels having hydraulic diameters of $0.133-0.367 \mathrm{~mm}$ and different geometric configurations. Their results indicated that the geometric configuration had a significant effect on the convection heat transfer for water and flow characteristics.

Experimental frictional pressure drop and heat transfer during single phase flow in a vertical mini-channel have been studied by $\mathrm{N}$. Caney et al. [14] with the aim of determining the validity of classical correlations available for conventional size channels. Their experimental frictional pressure drop measurements showed that, classical correlations accurately applyed. Also, temperature measurements along the channel showed that, the temperature profile was drastically different from the expected linear behavior owing to an important longitudinal heat flux in the channel wall.

Hydrodynamics and heat transfer in twodimensional mini-channels was studied by Reynaud et al. [15]. Their study was focused in the effect of macro-effects such as the effects of geometry or wall roughness on estimation of friction factor and the measured pressure drop along the whole channel as well as the local heat transfer coefficient. They showed good agreement between the experimental results and the values obtained from theoretical correlations.

The heat transfer coefficients in most of heat transfer measurements in small size channels seemed either higher or lower than classical heat transfer correlations. The deviations from classical heat transfer coefficients were clarified by two main factors. The first one was the method of measurement of the wall temperature as many artifacts in temperature measurements would be noticed as the thermocouples imbedded in the wall in the vicinity of the interface between the solid and the fluid and had access to the interface temperature by performing an interpolation of the thermocouples values. The second parameter was clearfield by the work of Maranzana et al. [16]. Their studies concerned with the heat flux distribution in the channel and consequently the fluid temperature distribution ceased to have a linear evolution along the channel axis.

Garimella et al. [17] studied developing flows in mini-channels and found a transition Reynolds number between 800 and 2000 for the heat transfer coefficient.

In general, it is clear from the previous published data that, there is no generally accepted model for the prediction of single phase heat transfer and pressure drop in mini-and micro-channels. Therefore, further systematic studies are required to generate a sufficient physical knowledge of the mechanisms that are responsible for the variation of the flow structure and heat transfer in mini-and micro-channels. In this work, an 
experimental study is done to investigate the effect of different operating parameters on the rate of heat transfer and pressure drop for polymer solution as well as water flow through multi-channels flat tube.

\section{EXPERIMENTAL APPARATUS}

An experimental apparatus is designed, fabricated and installed to study the pressure drop and convection heat transfer for flow inside flat Aluminum multi-channels extruded tube. $A$ schematic drawing for the experimental apparatus is shown in figure (1). Experimental apparatus consists of test section, working fluid open loop and heating steam loop.

Test section consists of five test chambers; with $10 \mathrm{~mm}$ apart; which enclosed the flat Aluminum multi-channels extruded tube. These test chambers are made from aluminum with 200 $\mathrm{mm}$ length, $120 \mathrm{~mm}$ wide and $60 \mathrm{~mm}$ height. Basic dimensions of the tested tube (Aluminum multi-channels extruded flat tube) are of $100 \mathrm{~mm}$ wide, $5 \mathrm{~mm}$ outer high and $1040 \mathrm{~mm}$ length. Flat tube composed of 22 parallel rectangular minichannels $(3.6 \mathrm{~mm} \times 3.85 \mathrm{~mm})$ with hydraulic diameter of $3.72 \mathrm{~mm}$. Both ends of the flat tube are equipped with $90^{\circ}$ Aluminum manifolds for fluid distribution. The tube diameter used for these manifolds is about four times the channel hydraulic diameter in order to suppress fluid distribution problem. All details of the test chamber is illustrated in figure (2). The steam is admitted from a distributer through three ports facing the flat tube upper surface as well as both flat tube sides, as shown in figure (2). By this way the steam was distributed uniformly around the flat tube. Test section is insulated with $4 \mathrm{~cm}$ of glass wool to minimize heat loss.

The working fluid polyacrylamide (dilute polymer solution) as well as water is drawn from a tank by using a centrifugal pump. The desired amount of flow rate is controlled by using a control valve located after the centrifugal pump, and the remaining return back to the inlet line. The supply line is fitted with a back pressure valve and a regulator to control the working fluid line pressure and adjust the mass flow rate. Working fluid flows through the inlet manifold of the flat tube and then flows inside 22 parallel rectangular mini-channels. Ditute polymer solutions with concentrations 10,20,50 and 100 ppm by weight are considered in this work. The working fluid mass flow rate is measured by using a turbine type flow meter. Two thermocouples of copper constantan type is fixed on the upper and lower flat tube surfaces in the middle of each test chamber, besides two thermocouples of copper constantan type are fixed at the working fluid line at inlet and outlet manifolds.

Heating steam loop consists of electric boiler, water separator and distributer. The basic dimensions of the electric boiler are $0.4 \mathrm{~m}$ in diameter and $1 \mathrm{~m}$ height. Three electric heaters (each one $3 \mathrm{~kW}$ rated power) are used. Each electric element is controlled through automatic switch with max load of $20 \mathrm{~A}$; to protect the boiler from aver load hazards. Safely valve was set to 2.5 bar and fixed at the upper port of the boiler. Also, pressure gauge was fit to the boiler upper port to monitor the steam pressure inside the boiler. The steam line includes a back pressure valve to assure the steady stream flow with a selected heating steam pressure, a regulator to control the amount of steam mass flow rate needed. The generated steam from clectric boiler is naturally moved to water separator and leaves it in dry saturated condition. Then, heating steam passes through the distributer. It is distributed to five test chanbers and condensed around the outer surface of the flat tube. The steam condensate is collected in a calibrated glass tube in a certain time to measure the condensate flow rate, and a thermocouple is fit to the condensate line to measure the condensate temperature at every test chamber.

\section{EXPERIMENTAL MEASUREMENTS}

The experimental measurements are taken to determine the friction factor and convection heat transfer coefficient for the working fluid which flows inside the flat Aluminum multi-channel extruded tube.

Pressure drop experiments are done at adiabatic condition for water flow inside the flat tube with a certain mass flow rate as well as the flow of polyacrylamide solution with different concentrations. Two pressure measuring ports 
are prepared at upstream and downstream of the test section to allow the direct measure of pressure drop across the test section. The two tubes are connected to a $U$ tube mercury manometer with an accuracy of $\pm 1 \mathrm{~mm} \mathrm{Hg}$. Working fluid volume flow rates measured by using a turbine type flow meter having a range of 0 to $10 \mathrm{Lit} / \mathrm{min}$ with an accuracy of $\pm 0.2 \%$ from full scale. Flow meter (type HFL2102A OMEGA Eng. Inc.) is calibrated using a constant volume tank and stop watch.

For heat transfer experiments, the experimental apparatus is allowed to operate until the fluctuation in temperatures was about $\pm 0.1^{\circ} \mathrm{C}$. Then, steady state condition is reached. Once the system is reached to the desired steady state condition, the required measurements of temperature, pressure and volume flow rate are taken. The inlet and outlet temperatures for the working fluid and other temperatures in different positions are measured by using copper constantan thermocouple wires. Upper and lower surface temperatures are measured along the flat tube length for five chambers. Temperatures of heating steam at inlet and condensate outlet from each test chamber are measured. The uncertainty in temperature measurements is $\pm 0.1^{\circ} \mathrm{C}$. Due to the small amount of condensate from each test chamber a calibrated constant volume tank and stop watch is used. Inlet steam pressure is measured by Bourdon pressure gauge with minimum readable value of \pm 0.05 bar.

The root-mean-square random error propagation analysis is carried out in the standard fashion using the measured experimental uncertainties of the basic independent parameters. The experimental uncertainties associated with these measurements technique are estimated to be approximately less than $7.1 \%$ for Reynolds number and less than 7.5 and $8.3 \%$ for friction factor and Nusselt number respectively.

\section{TEST PROCCEEDURE}

The steps of measuring the parameters affected heat transfer experiment as follows:

1- Begin to fill the boiler with water up to a level of $730 \mathrm{~mm}$.

2- Switch on the heaters from the control panel.
3- Wait until water to be boiled.

4- Open the vent valve on the boiler top port to vent the air inside the boiler.

5- Close the main valve on the boiler until the pressure gage was reaching to 2 bar absolute.

6- Adjust the back pressure valve on the steam line to 1.2 bar absolute and regulate the required amount of steam.

7- Switch the centrifugal pump on to allow the water flow through the flat tube and adjust the back pressure valve and the water flow regulator and then read the volume flow rate using the turbine type flow meter.

8- The ternperature readings of the thermocouples at the upper and lower surfaces of flat tube will be carefully noticed until the fluctuation in temperature readings was about $\pm 0.1{ }^{0} \mathrm{C}$, then steady state condition is reached. The required measurements of temperature, pressure and volume flow rate are taken.

9- Read the condensate volume flow rate as well as the temperature readings on both the steam and water lines.

10-Repeat the steps 7 till 9 with adding polyacrylamide by several concentrations: $10,20,50$ and $100 \mathrm{ppm}$.

\section{DATA REDUCTION}

The basic measurements are analyzed using a computer reduction program to calculate the friction factor and convection heat transfer coefficient and in turn Nusselt number for the working fluid which flows inside the flat tube.

\subsection{Pressure drop}

The measured adiabatic pressure drop includes frictional, entrance and exit components. The entrance and exit components are small and may be neglected. Therefore, the measured pressure drop $(\Delta \mathrm{P})$ for the working fluid is then directly related to the frictional pressure drop. The friction factor ( $f$ ) is obtained from the pressure drop measurements through the tested tube as;

$f=\frac{2(\Delta P) d_{l y d d}}{\rho u^{2} L}$ 
Where:

$\rho$ : Working fluid density.

$u$ : Working fluid average velocity.

$L$ and $d_{h y d}$ : Flat tube length and hydraulic diameter for each channel of flat tube respectively.

\subsection{Heat transfer}

At steady state, the total input heat from the heating steam $\left(Q_{s t}\right)$ can be divided into useful heat to the working fluid which flows inside the flat tube ( $Q_{u s}$ ) and the remaining amount of heat transferred to the suroundings as heat loss ( $Q_{\text {loss }}$ ). The total input heat can be determined from the summation of input heat to each one from five test chambers as follow;

$\mathrm{Q}_{\mathrm{st}}=\sum_{\mathrm{j}=1}^{3} \dot{\mathrm{m}}_{\mathrm{s}, \mathrm{j}}\left(\mathrm{i}_{\mathrm{s}}-\mathrm{i}_{0}\right)_{\mathrm{j}}$

Where;

$\dot{m}_{s 1, j}$ : Steam flow rate inside test chamber number $\mathrm{j}$.

$\left(i_{E}-i_{0}\right)$ : Specific enthalpy difference along test chamber number $\mathrm{j}$.

$i_{g}$ : Specific enthalpy for dry saturated steam evaluated at the steam inlet pressure to the test chamber.

$i_{0}$ : Specific enthalpy for condensate at the outlet from test chamber.

The useful heat can be calculated from measuring working fluid mass flow rate which flow inside the flat tube and the temperature rise in the working fluid as;

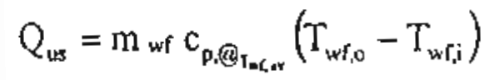

Where:

in w : Mass flow rate of the working fluid.

$c_{p\left(I_{1, \ldots}\right.}$ : Specific heat of workingftuid al mean bulk lemperature.

$\tau_{w, f_{0}}$ :Outlet working fluid temperature.

$T_{w i, i}$ : Inlet working fluid temperature.

Due to small concentration of polymer; the working fluid properties for polymer solution is considered similar to water and calculated at average bulk temperature, $T_{\mathrm{wf}, \mathrm{gv}}=\left(\mathrm{T}_{\mathrm{wf}, \mathrm{i}}+\mathrm{T}_{\mathrm{wf}, 0}\right) / 2$.

Then, the amount of heat loss from the test section to the surrounding air (Qloss) can be determined as the difference between input heat and useful heat as;

$Q_{\text {loss }}=Q_{s t}-Q_{u s}$

The heat flux ( $q^{\prime \prime}$ can be calculated from the following equation as;

$q^{\prime \prime}=Q_{u s} / A_{s}$

Where;

$A_{s}=$ Surface area for flat tube, $\left(A_{s}=2\left(w+e_{3}\right) L\right)$. Also; $w$ and $L$ are the flat tube width and length respectively.

The average value for the inner surface temperature of the flat tube $\left(T_{5, i}\right)$ is needed to calculate the convection heat transfer coefficient. The thermocouples are fixed on the external flat tube surface to measure the local upper and lower surface temperatures. The average value for the outer surface temperature of the flat tube $\left(T_{5,0}\right)$ can be calculated by taking the average of ten measured experimental values for local upper and lower surface temperatures. Therefore; by solving the heat conduction equation, the tcmperature difference $\left(T_{5,0}-T_{s, i}\right)$ is obtained. It is found finally that, $\left(T_{s, 0}-T_{s, i}\right)$ yields a value less than $0.1^{\circ} \mathrm{C}$. Since the temperature difference is less than the uncertainty on temperature difference $\left(0.142{ }^{\circ} \mathrm{C}\right)$. The outer surface temperature of the flat tube $\left(\mathrm{T}_{\mathrm{s}, \mathrm{o}}\right)$ could be taken as the inner surface temperature $\left(T_{s, i}\right)$.

Accordingly, the convection heat transfer cocfficient ( $h$ ) can be calculated as;

$\left.\mathrm{h}=\left(\frac{\mathrm{q}^{\prime \prime}}{\left(\mathrm{T}_{\mathrm{s}, \mathrm{i}}-\mathrm{T}_{\mathrm{wf,av}}\right.}\right)\right)$

Where:

$\mathrm{h}$ : Convective heat transfer coefficient.

$T_{s, i}$ : Average value for the inner surface temperature of the flat tube.

Reynolds number could be evaluated as, 
$\operatorname{Re}=\frac{u * d_{\text {hyd }}}{v}$

Where:

$u$ : Working fluid average velocity inside the multi-channels flat tube.

$\mathrm{d}_{\text {hyd }}$ : Hydraulic diameter of the mini channel $\left(d_{h y d}=2 e_{1} e_{2} /\left(e_{1}+e_{2}\right)\right)$.

$e_{1}$ : Channel height.

$\mathrm{e}_{2}$ : Channel width.

$v$ : Kinematic viscosity of working fluid evaluated at average bulk temperature.

The average values for the Nusselt number (Nu), could be evaluated as,

$N u=\frac{h * d_{t y d d}}{k}$

Where, $\mathrm{k}$ : Thermal conductivity for working fluid.

The Prandile number defined as,

$$
\operatorname{Pr}=\frac{\mu c_{p}}{k}
$$

Where:

$\mu$ : Dynamic viscosity for the working fluid.

While the Poiseuille number (Po) is defined according to the following equations as;

$P_{0}=f * \operatorname{Re}$

\section{RESULTS AND DISCUSSIONS}

Study of low and heat transfer for water and polymer solution with different concentrations flowing inside multi-channels flat tube was performed. Heating source was condensation of dry saturated steam on the outer surface of the tested tube. Pressure drop and heat transfer experiments were conducted to compute friction factor and Nusslet number for the working fluid.

\subsection{Validation of the experimental apparatus}

To verify the validity of the experimental apparatus a comparison between the obtained experimental results for water flow inside the multi-channels flat tube is compared with the previous results for friction factor and Nusselt number.

The friction factor evaluated from the measured pressure drop for the multi-channels flat tube is plotted with the different values of Reynolds number, as shown in figure (3). The comparison between the obtained experimental results for water flow inside the multi-channels flat tube with the conventional correlation for laminar flow inside smooth rectangular channel was presented in figure (3). It is noticed that, friction factor for water flow inside the flat tube is in good agreement with the classical value for laminar flow for the flow inside rectangular channel up to $\operatorname{Re}=1100$, with aspect ratio nearly equals one,$(f=56.92 / \mathrm{Re})$. It is observed that, a remarkable deviation of experimental friction factor values from the conventional value for rectangular channel in the transition region from laminar to turbulent flow occurs at Reynolds number in the range of 1100-2000, which is in agreement with the search work of Agostini et al. (2004) for the laminar-turbulent transition occurs for mini-channels at $1800 \leq \operatorname{Re} \leq 2000$.

Results found in literature about heat transfer in mini-channels for single phase flow are often contradictory and operating conditions change from one study to another, so that geometry or fluid distribulion are often missing which could explain a discrepancy in results. Figure (4) shows, a comparison between the present experimentally work with others. The average Nusselt number takes somewhat a higher value than the fully developed laminar flow inside conventional tube. Agostini (2004) conducted the experimental work on a rectangular channel where $\mathrm{d}_{\mathrm{hyd}}=1.17 \mathrm{~mm}$ where the present work deals with rectangular channel of, $d_{\text {hyd }}=3.72 \mathrm{~mm}$. Peng and Peterson (1996) studied forced convection for water flow inside micro-channel with hydraulic diameter, $\mathrm{d}_{\text {hyd }}=0.133-0.367 \mathrm{~mm}$. Comparison between the obtained experimental results with the previous work gave the same trend.

\subsection{Hydrodynamic Results}

Figure (5) shows the variation of the measured pressure drop with different values of Reynolds number. The pressure drop presented for flow of polymer solutions with different 
concentrations inside the multi-channels flat tube compared with the pressure drop for water flow. It is observed, an increase in pressure drop with increasing Reynolds number for flow of polymer solutions as well as the water flow inside the flat tube. The careful examination of the pressure drop variation with the different values of Reynolds number in the laminar regime up to $\mathrm{Re}$ $=1100$ shows that the pressure drop takes higher values for flow of polymer solutions compared with water flow. In contrast the pressure drop for the water flow will be outweighs that for the flow of polymer solutions in the onset of turbulent regime for values of Reynolds number $\operatorname{Re}>1100$. This behavior was a consequence of the turbulent flow only for the dilute polymer solutions causes drag reduction, phenomena observed as the findings of search work of Rabie, et al. (1990).

Figure (6) illustrates the friction factor extracted from the measured pressure drop with different values of Reynolds number for flow of polymer solutions as well as water flow inside the multi-channels flat tube. It is noticed that. friction factor for polymer solutions is highly dependent on the concentration and there is some dispersion between the experimental friction factor results and the classical value for laminar flow in rectangular channel.

Figure (7) illustrates the Poiscuille number extracted from the measured pressure drop with different values of Reynolds number for flow of polymer solutions as well as water flow inside the multi-channels flat tube. It is observed that, Poiseuille number for water flow was in good agreement with the classical value for laminar flow inside rectangular channel with aspect ratio nearly equals one ( $P o=56.92)$. Figure (7) reclaimed higher values of Poiseuille number of about 120 for polymer solutions with different concentrations in the studied operating range. The deviation from the classical theory values for polymer solutions can be explained as the polymer near the wall became fully stretched, due to the large strain rates near the wall, and consequently an increase of the fluid viscosity in this region. The present study reclaims for flow of polymer solutions with different concentrations, in the laminar-turbulent transition region, $1100 \leq \operatorname{Re} \leq 2000$, the effects

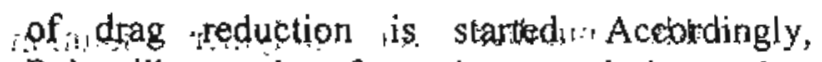
Poiseuille number for polymer solutions takes lower values compared with water.

\subsection{Heat Transfer Results}

Local temperatures of the upper and lower surface for flat tube were measured along the test section length at five positions for all experiments. Figure (8) shows local surface temperature versus dimensionless test section length for polymer solution concentration ratios (20 ppm and $50 \mathrm{ppm}$ ) compared with water for $R e=840$ and heat flux $q^{\prime \prime}=41 \mathrm{~kW} / \mathrm{m}^{2}$. Surface temperature for lower surface takes higher values than upper surface for both polymer solution as well as water due to high thermal resistance for heat flow to the lower surface. Also, both upper and lower surface temperature takes higher values when using polymer solution compared with water. Figure (8) shows a linear distribution of the local temperatures of the upper and lower surfaces except at the entrance of flat tube, where the boundary layer development affects the temperature distribution.

Maranzana et al. [16] introduce a parameter $M$ to compare longitudinal conduction heat flux along the channel walls to the flux which is conveyed by convection as:

$M=\frac{k_{\psi}\left(\frac{\delta_{w}}{L}\right)}{\rho c_{p} \delta_{b} u}$

Where:

$k_{w}$ : The wall conductivity.

$\delta_{p}:$ The wall thickness.

$\delta_{b}$ : The fluid themnal boundary layer thickness.

The value of Maranzana factor in the range of Reynolds number of $200 \leq \mathrm{Re} \leq 2000$ will be in the range of $0.002 \leq M \leq 0.02$. The axial heat flux becomes significant when the parameter $M$ becomes greater than 0.01 . On the other hand the selected value of Reynolds number equals to 840 to conduct the local temperatures of the upper and lower surfaces, figure(8) will not affected by the axial heat conduction since the Maranzana factor will be in the order of 0.008 which was away from the critical value $(0.01)$.

Figure (9) shows; the variation of upper and lower average surface temperatures versus 
Reynolds number for polymer solution concentration ratios (20 ppm and $50 \mathrm{ppm}$ ) and water. It is noticed that, average surface temperature decreases with increasing $\mathrm{Re}$ for both polymer solution and water. Also, both upper and lower average surface temperature takes higher values when using polymer solution compared with water. The average surface temperature for the upper and lower flat tube surfaces will have some deviation from the linear distribution for lower values of Reynolds number, figure $(9)$.

Figure (10) represented the distribution of the temperature difference between the average surface temperature and the average bulk temperature of the working fluid, $\left(\mathrm{T}_{\mathrm{s}, \mathrm{av}}-\mathrm{T}_{\mathrm{wr}, \mathrm{av}}\right)$ versus Reynolds number. The direct comparison between the temperature difference, for flow of polymer solutions with concentrations $10,20,50$ and $100 \mathrm{ppm}$ with the temperature difference for water flow exhibit higher values of the temperalure difference when using polymer solutions. This behavior is explained as a result of high thermal resistance for heat flow especially for the laminar flow region, $\mathrm{Re} \leq 1100$. The reduction in heat transfer, noticed for flow of polymer solutions with different concentrations due to frictional drag is found.

The variation of the average Nusselt number (Nu) with different values of Reynolds number (Re) for flow of polymer solution with different concentrations inside the multi-channels flat tube as well as the water flow will illustrated in figure (11). Nusselt number increases with the increase in Reynolds number. The average Nusslet number for flow of polymer solution with different concentrations exhibits lower values than that for water flow inside the flat tube. It is known that the value of the average Nusslet number will be affected with many parameters such as; the flow Reynolds number, Prandtle number, the type of flow pattern either laminar or turbulent.

Figure (12) shows the variation of $\mathrm{Nu}_{\text {poly }} / \mathrm{Nu}_{\mathrm{w}}$ versus polymer concentrations for different values of Reynolds number. It is observed that, the reduction in Nusselt number increases with increasing polymer concentration. Also, the reduction in $\mathrm{Nu}$ increases with decreasing Reynolds number. Therefore, the average value for decrease in $\mathrm{Nu}$ for polymer solution than water is about $15 \%$.

In the present study a correlation for the Nusslet number is suggested from the collected data for flow of polymer solution with different concentrations inside the multi-channels flat tube as well as the water flow. The correlation will start from the correlation of Sieder-Tate. The proposed correlation will pay attention to the polymer solution as well as the effect of the corners of the rectangular channels. The index of Reynolds number in the proposed correlation was selected to be 0.53 and then the suggested correlation will be:

$N_{L}=1.86 \operatorname{Re}^{[0.53)}\left(\frac{\operatorname{Pr} D}{L}\right)^{\frac{1}{3}}\left(1-\left(\frac{p p m}{10^{6}}\right)^{0.33}\right)$

Figure (13) presents the deviation between the present work experimental findings of Nusslet number and the calculated Nusslet number according to the correlation suggested in the present study. The maximum error in the calculated values for Nusselt number by the above suggested correlation is found to be nearly $\pm 20 \%$, as shown in figure (13).

\section{CONCLOUSIONS}

Convection heat transfer and pressure drop for dilute polymer solutions and water flow inside multi-channels flat tube is investigated experimentally.

It is concluded that, the laminar turbulent transition occurs at $\operatorname{Re}=1100-2000$. Pressure drop and in turn friction factor takes higher values for laminar flow of polymer solutions compared with water. Poiseuille number for water flow inside the flat tube is in good agreement with the classical value for rectangular channel with aspect ratio nearly equals one, $(f=56.92 / \mathrm{Re})$. On the other hand Poiseuille number takes higher value about 120 for polymer solution with different concentrations in the studied operating range. Convection heat transfer coefficient and in turn Nusselt number were decreased when using polymer solutions compared with water. The reduction value in $\mathrm{Nu}$ increases with increasing concentration of polymer solution. The average value for this reduction in $\mathrm{Nu}$ is about $15 \%$. 
An empirical correlation for Nusselt number is obtained in the range of the studied operating parameters. Comparison between the obtained experimental results with the previous data is done and gives the same trend.

\section{REFERENCES}

1- S.S. Mehendale, A.M. Jacobi, R.K. Shah, Fluid flow and heat transfer at micro and meso-scales with applications to heat exchanger design, Appl. Mech. Rev. 53 (2000) 175-193.

2- S.G. Kandlikar, W.J. Grande, Evolution of micro channel flow passages - thermo hydraulic performance and fabrication technology, Heat Transfer Eng. 24 (1) (2003) 3-17.

3- R. Bavie're, S. Le Person, F. Ayela, M Favre-Marinel, An experimental study of water flow in smooth and rectangular microchannels, Proc. 2nd Int. Conf. Micro channels and Mini-channels, Rochester, New York, USA, ASME, 2004.

4- R. Shah, A. London, Laminar flow forced convection in ducls, Advances in Heat Transfer, Academic Press, 1978.

5- P. Gao, S. Le Person, M. Favre-Marinet, Scale effects on hydrodynamics and heat transfer in two-dimensional mini and micro channels, Int. J. Therm. Sci. 41 (2002) $1017-$ 1027.

6- L.H. Rabie, M.S. El Kady and M.M. Abd Elaall, Turbulent diffusion from a point source in a uniform flow of viscoclastic fluids, 3rd Intemational congress of fluid mechanics, Vol, IV, No. 25, pp. 1325-1341, (1990).

7- L.H. Rabie, M.A. Tolba, F.F. Araid and M.M. Awad, Constant wall temperature heat transfer in drag reducing fluid flows, Mansoura Engineering Bulletin, Vol. 11, No. 2, M71, (1986).

8- E.Y. Kawack, Y.I. Cho, and J. P. Hartnett, Heat transfer to polyacrylamide solutions in turbulent pipe flow, AIChE $f$, 27, pp.123.,(1981)

9- P.M. Debrule, and R.H. Sabersky, Heat transfer and friction coefficient in smooth and rough tubes with dilute polymer solutions, Int. J. Heat Mass Transfer, 17, (1972).

10-P. Rosa, T.G. Karayiannis and M.W. Collins, Single-phase heat transfer in micro-channels: The importance of scaling effects, Applied Thermal Eng., 29 (2009) 3447-3468.

$11-P$. Naphon and O. Khonseur, Study on the convection heat transfer and pressure drop in the micro-channel heat sink, Int. Communication in Heat and Mass Transfer 36(2009)39-44.

12-B. Agostini, B. Watel, A. Bontemps and B. Thonon, Friction factor and heat transfer coefficient of R134a liquid flow in minichannels, Applied Thermal Engineering Vol. 22, (2002) pp. 1821-1834.

13-X.F. Peng, G.P. Peterson, Convective heat transfer and flow friction for water flow in micro-channel structures, Int. J. Heat Mass Tratisfer 39 (1996) 2599-2608.

14-N. Caney, P. Marty, J. Bigot, Friction losses and heat transfer of single-phase flow in a mini-channel, Applied Thermal Engineering 27 (2007) 1715-1721.

15-S. Reynaud, F. Debray, J. Franc, T. Maitre, Hydrodynamics and heat transfer in twodimensional mini-channels, International Journal of Heat and Mass Transfer 48 (2005) 3197-3211.

16-G. Maranzana, I. Perry, D. Maillet, Mini- and micro-channels: Influence of axial conduction in the walls, Int. J. Heat Mass Transfer 7 (2004) 3993-4004.

17-S. Grimella W. Dowling, M.V.D. Veen, J. Killion, The effect of simultaneousty developing flow on heat transfer in rectangular tubes, Heat Transfer Engineering 22 , no. $6(2001)$ 


\section{NOMENCLA TURE}

$A_{s}$ : Surface area, $m^{2}$

cp : Specific heat, $\mathrm{J} / \mathrm{kg} .{ }^{\circ} \mathrm{C}$

$d_{1 y} \quad$ : Hydraulic diameter $\left(d_{h y d}=2 e_{1} e_{2} /\left(e_{1}+e_{2}\right)\right)$,

d $\mathrm{m}$

$e_{1}$ : Channel feight, $m$

$e_{2} \quad$ : Channel width, $m$

$e_{3} \quad$ Flat tube outer height $\left(e_{3}=e_{1}+2 t\right), m$

$f$ : Friction factor.-

h: Convection heat transfer coefficient, $\mathrm{W} / \mathrm{m}^{2}$, ${ }^{0} \mathrm{C}$

i : Specific enthalpy, J/kg

$k \quad$ : Thermal conductivity, $\mathrm{W} / \mathrm{m} .{ }^{\circ} \mathrm{C}$

L : Flat tube length, $m$

m : Mass flow rate, $\mathrm{kg} / \mathrm{s}$

Nu : Nusselt number (Nu $\left.=11 d_{\text {lyd }} / k\right)$, -

$\mathrm{P} \quad$ : Pressure, $\mathrm{Pa}$

Po : Poiseuille number ( $\mathrm{Po}=\mathrm{fRe})$,

Pr : Prandtl number $\left(\mathrm{Pr}_{\mathrm{r}}=\mathrm{c}_{\rho} \mu / \mathrm{k}\right)$,

Q : Heat bransfer rate, $W$

$q^{\prime \prime} \quad$ : Heat flux, W/m $\mathrm{m}^{2}$

Re :Reynolds number $\left(\operatorname{Re}=\rho{ }^{\prime} d_{\text {hyd }} / \mu\right)$.

$\mathrm{T}$ : Temperature, ${ }^{\circ} \mathrm{C}$

1 : Flat tube wall thickness, m y :Working fluid average velocity, $\mathrm{m} / \mathrm{s}$

w : Flat tube width, m

Greek symbols

$\Delta \mathrm{P} \quad$ : Pressure drop, $\mathrm{Pa}$

$\mu \quad$ : Dynamic viscosity, $\mathrm{kg} / \mathrm{m} . \mathrm{s}$

$\rho \quad:$ Density, $\mathrm{kg} / \mathrm{m}^{3}$

$v \quad$ : Kinernatic viscosity, $\mathrm{m}^{2} / \mathrm{s}$

Subscripts

$\begin{array}{ll}\text { av } & \text { : average } \\ \mathrm{g} & \text { : Dry saturated steam } \\ \text { hyd } & \text { : hydraulic } \\ \mathrm{i} & \text { : inner, inlet } \\ \text { loss } & \text { : loss } \\ \text { a } & \text { : outlet } \\ \text { poly } & \text { : polymer } \\ \text { s } & \text { : surface } \\ \text { st } & \text { : steam } \\ \text { us } & \text { : useful } \\ \text { w } & \text { : water } \\ \text { wf } & \text { : working fluid }\end{array}$

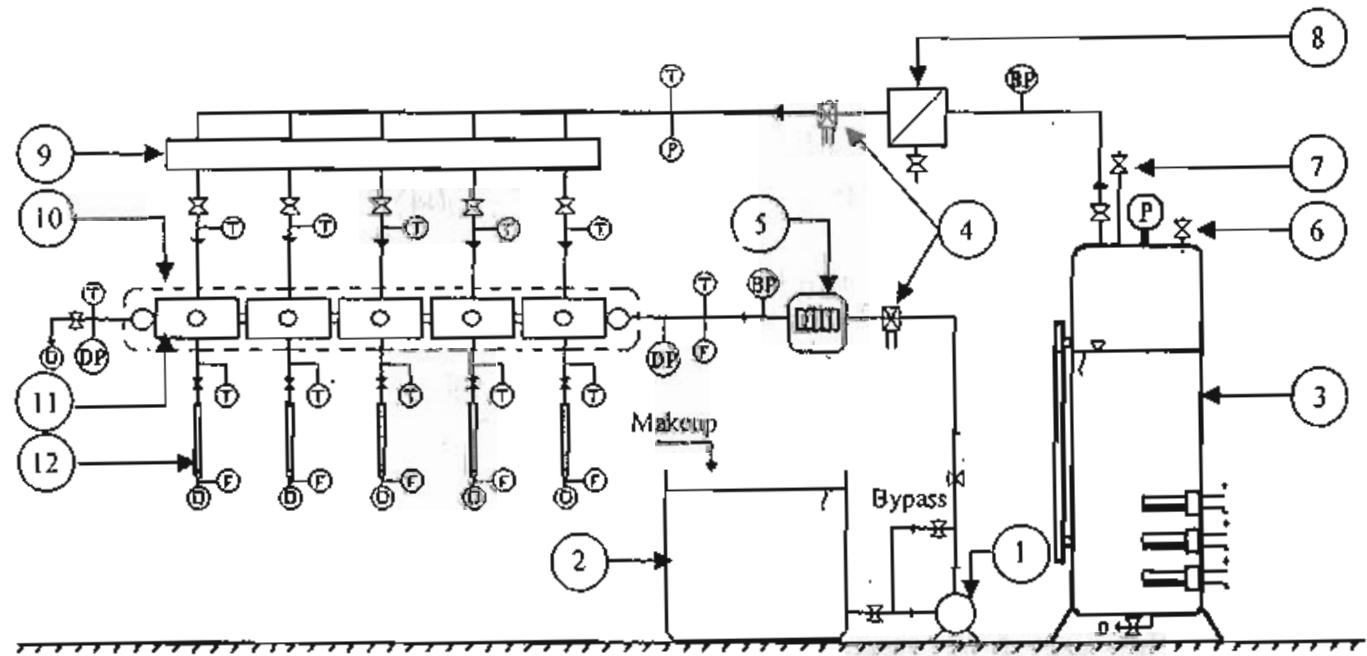
1. Centrifugal pump.
2. Working fluid tank.
3. Electric boiler.
4. Regulator.
5. Flow meter.
6. Safety valve.
7. Vent valve.
8. Water separator.
9. Distributer.
10. Test Section.
11. Test chamber.
12. Burette.
BP: Back pressure.
D: Drain.
DP: Pressure Difference.
F: Flow Rate.
P: Pressure gauge.
T: Temperature.

Figure (1) Schematic diagram for the experimental apparatus. 
M. 39 Hesham M. Mostafa and Tarek F. Oda

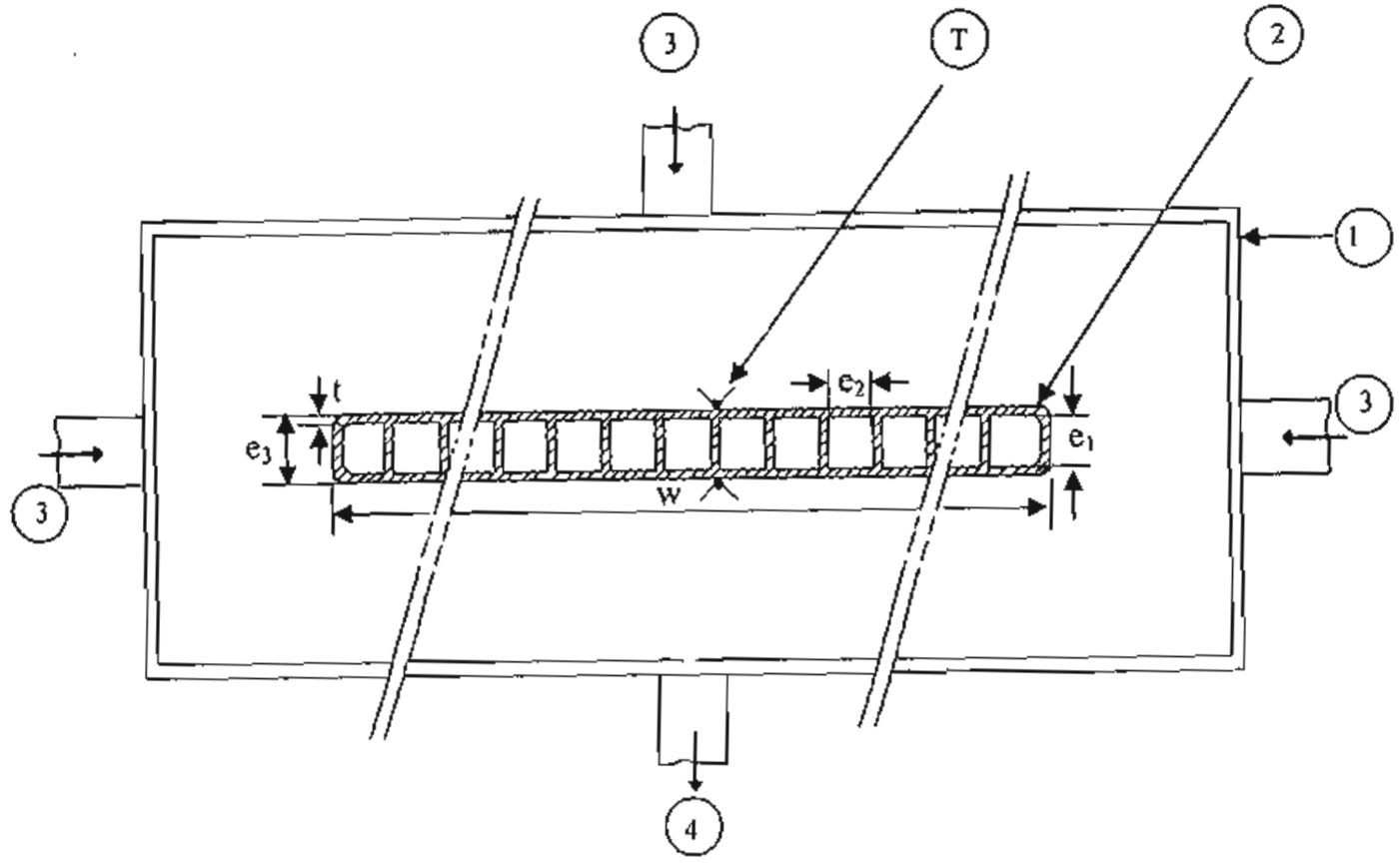

1.Test chamber. 2. Flat Tube. 3. Inlet heating steam.

4. Condensate. T: Temperature.

Figure (2) Test chamber details.

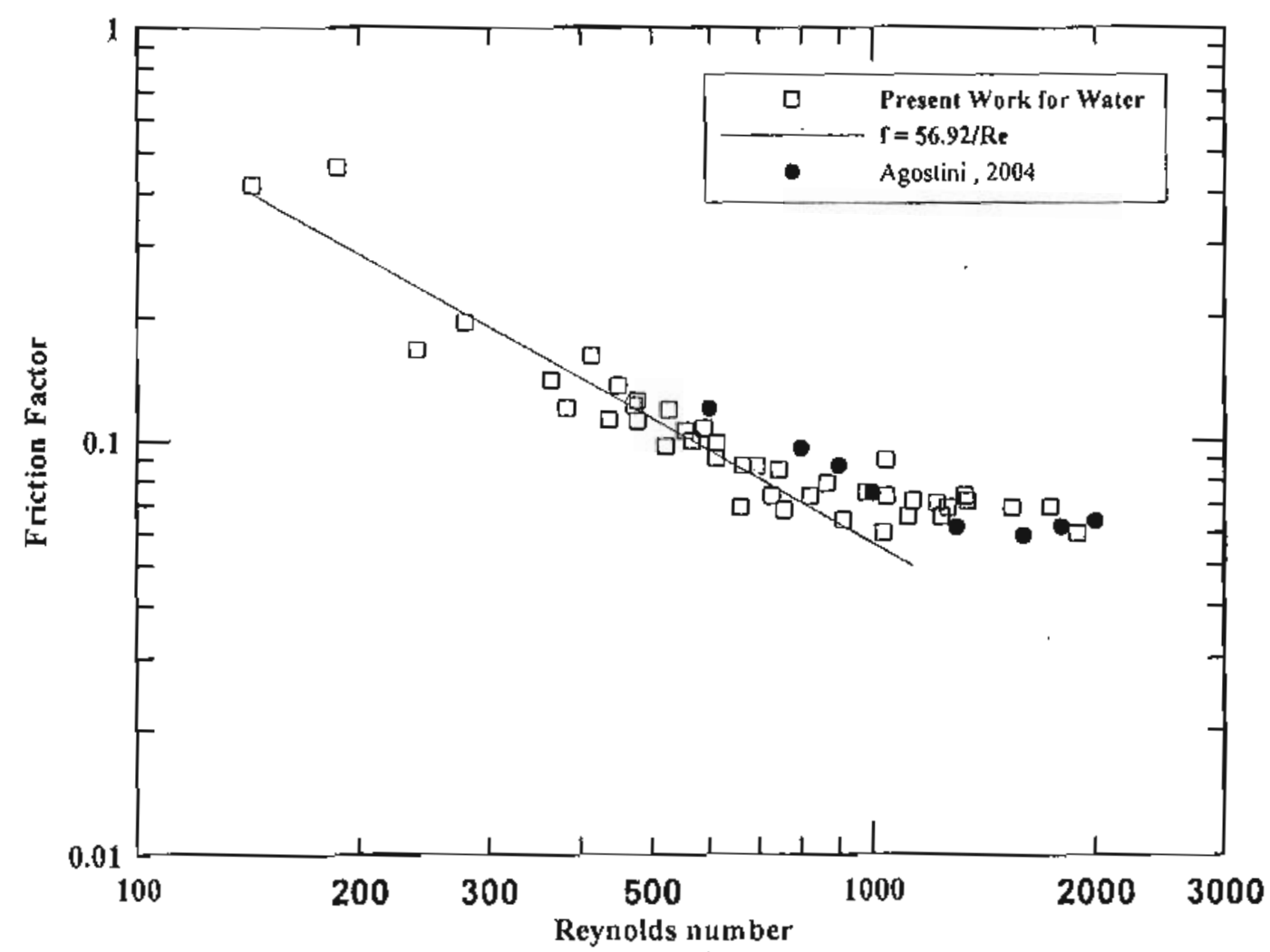

Figure (3) The variation of friction factor against Reynolds number for Water compared with Agostiti, 2004 and conventional reclangular channel $(f=56.92 / \mathrm{Re})$. 


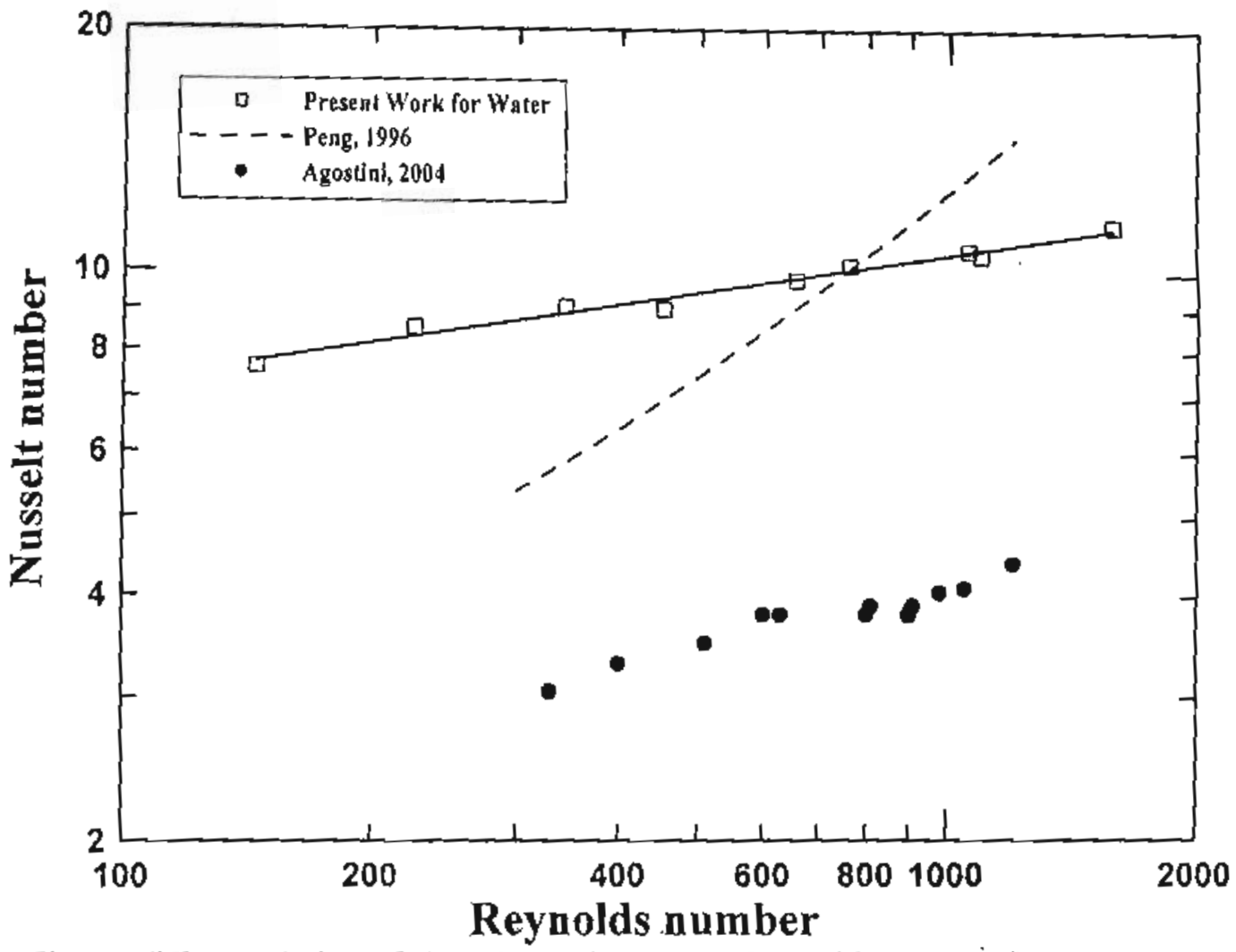

Figure (4)The variation of Nusselt number versus Reynolds number for the present work for water compared with the previous work.

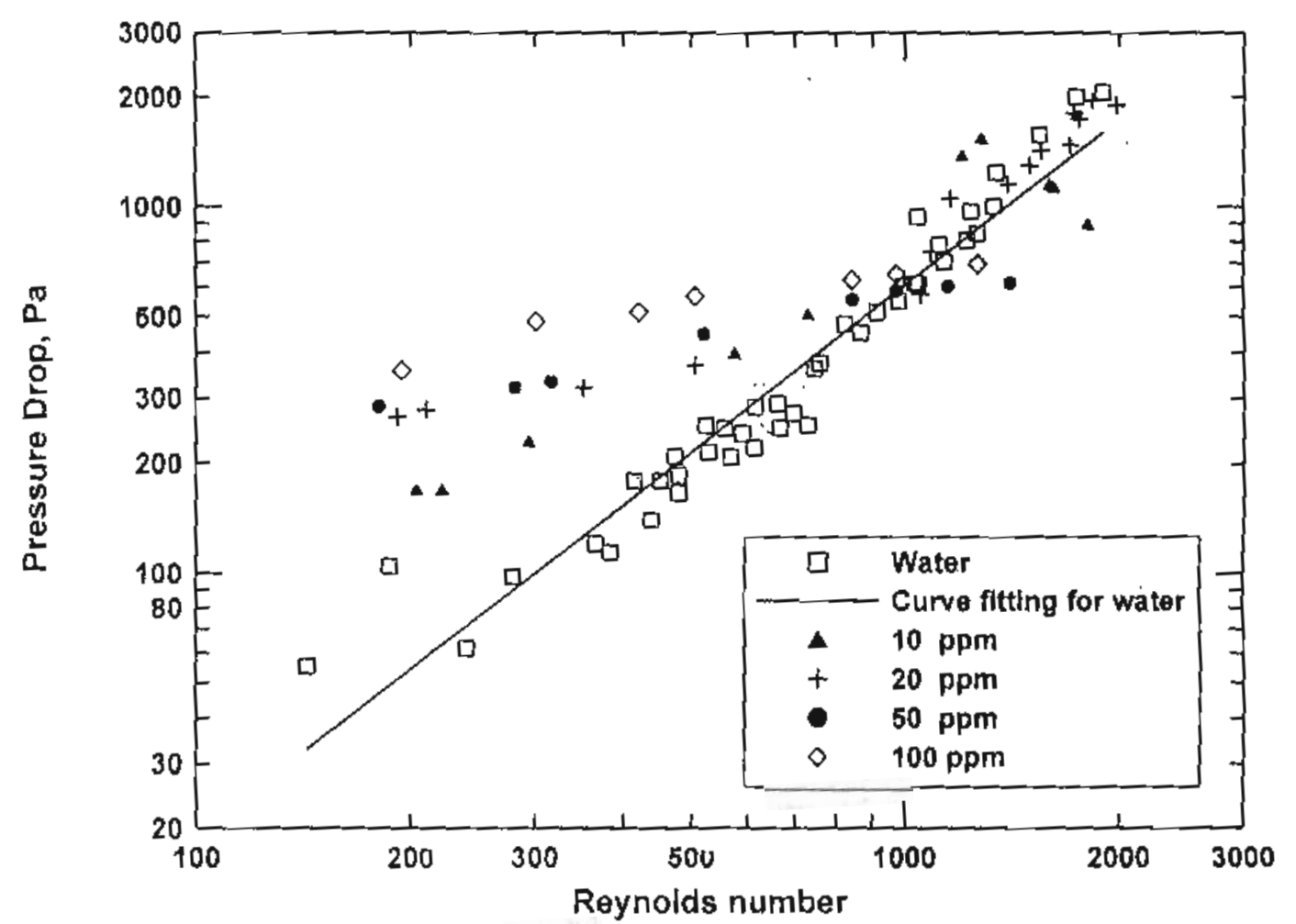

Figure (5) Variation of the measured pressure dtop versus Reynolds number for polymer solutions compared with water. 
M. 41 Hesham M. Mostafa and Tarek F. Oda

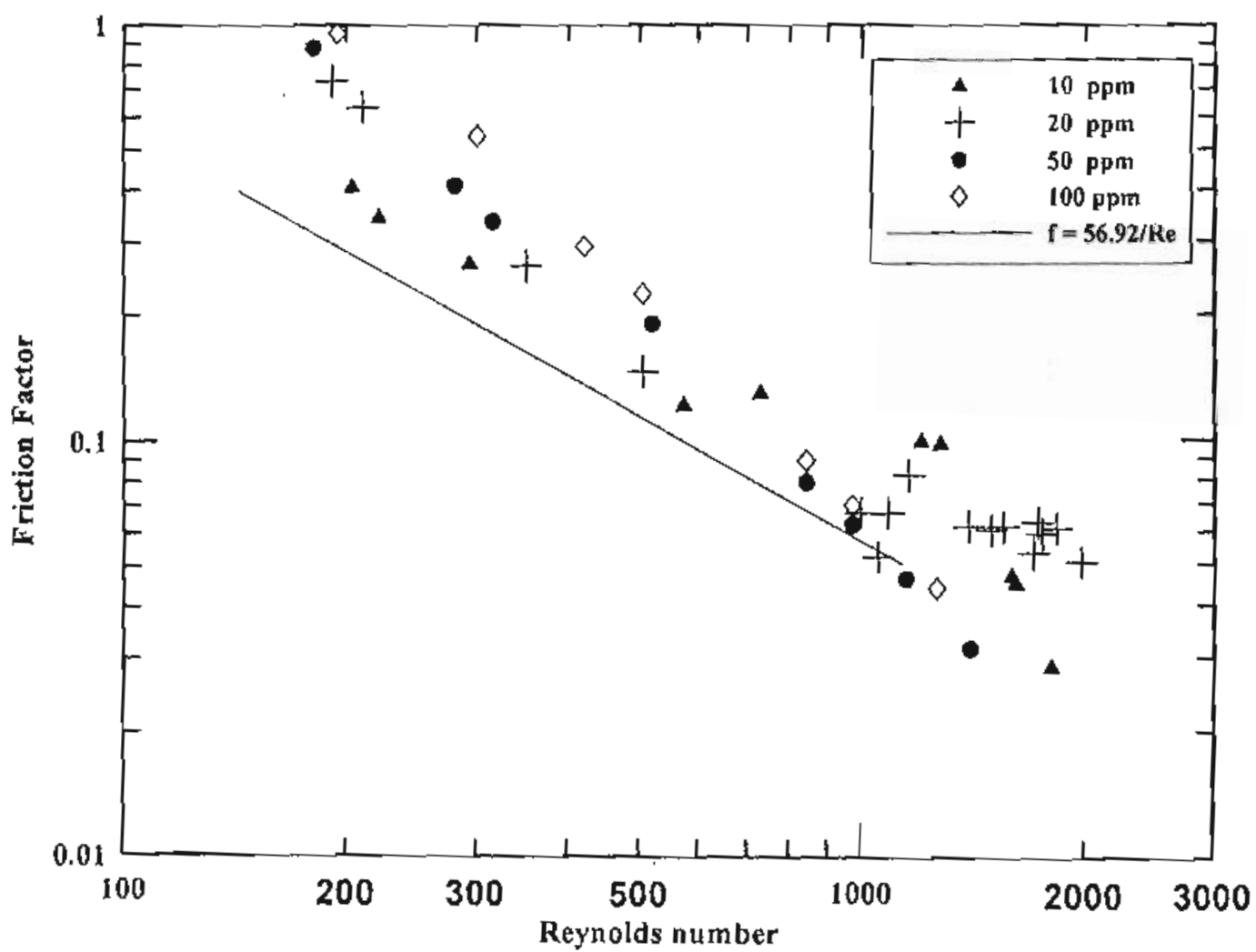

Figure(6) Friction factor against Reynolds number for polymer solutions compared with conventional rectangular channel ( $f=56.92 / \mathrm{Re}$ ).

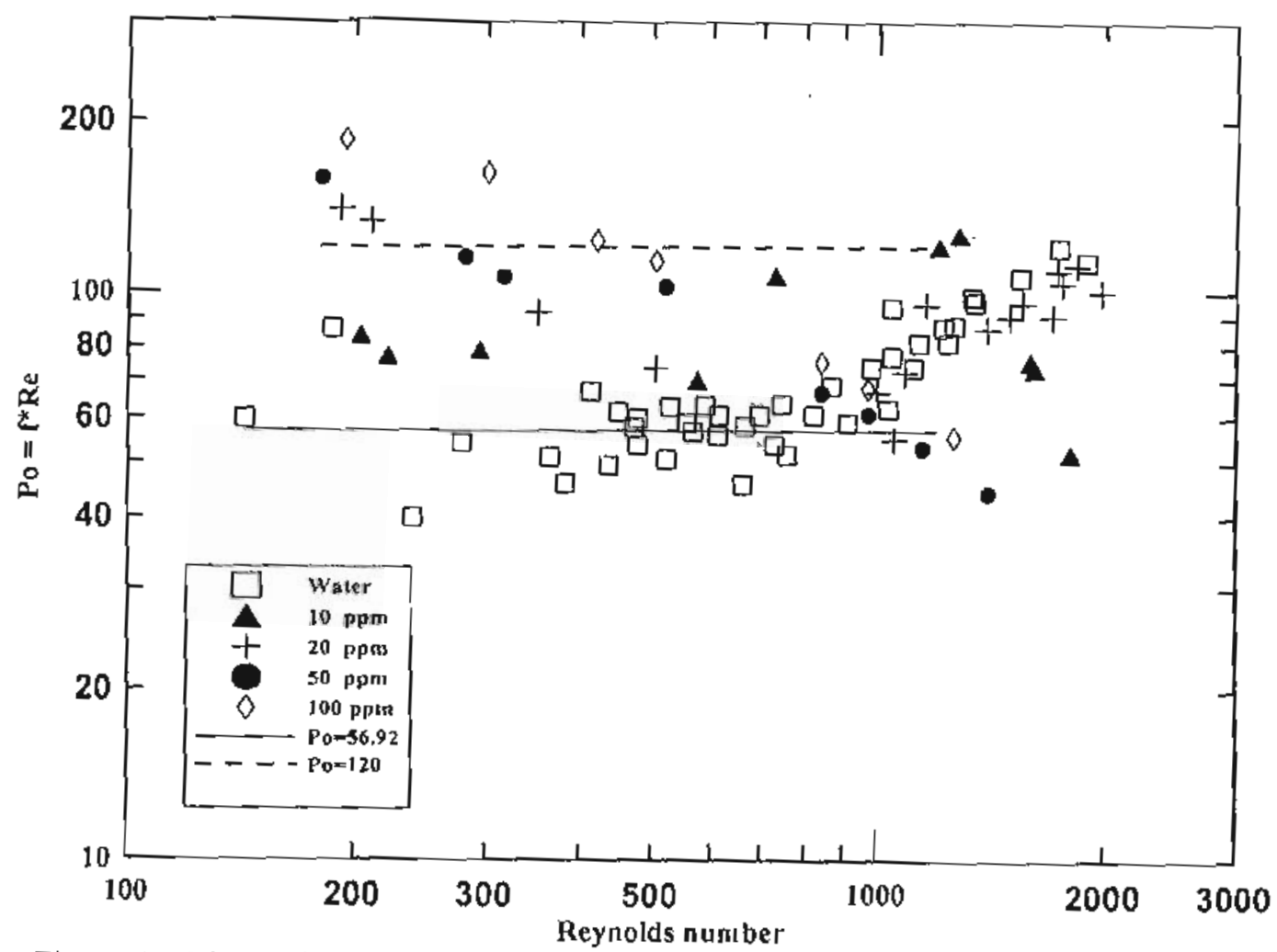

Figure (7) The variation of Poiseuille number with Reynolds number for the present work with respect to the conventional rectangular channel (Po=56.92). 


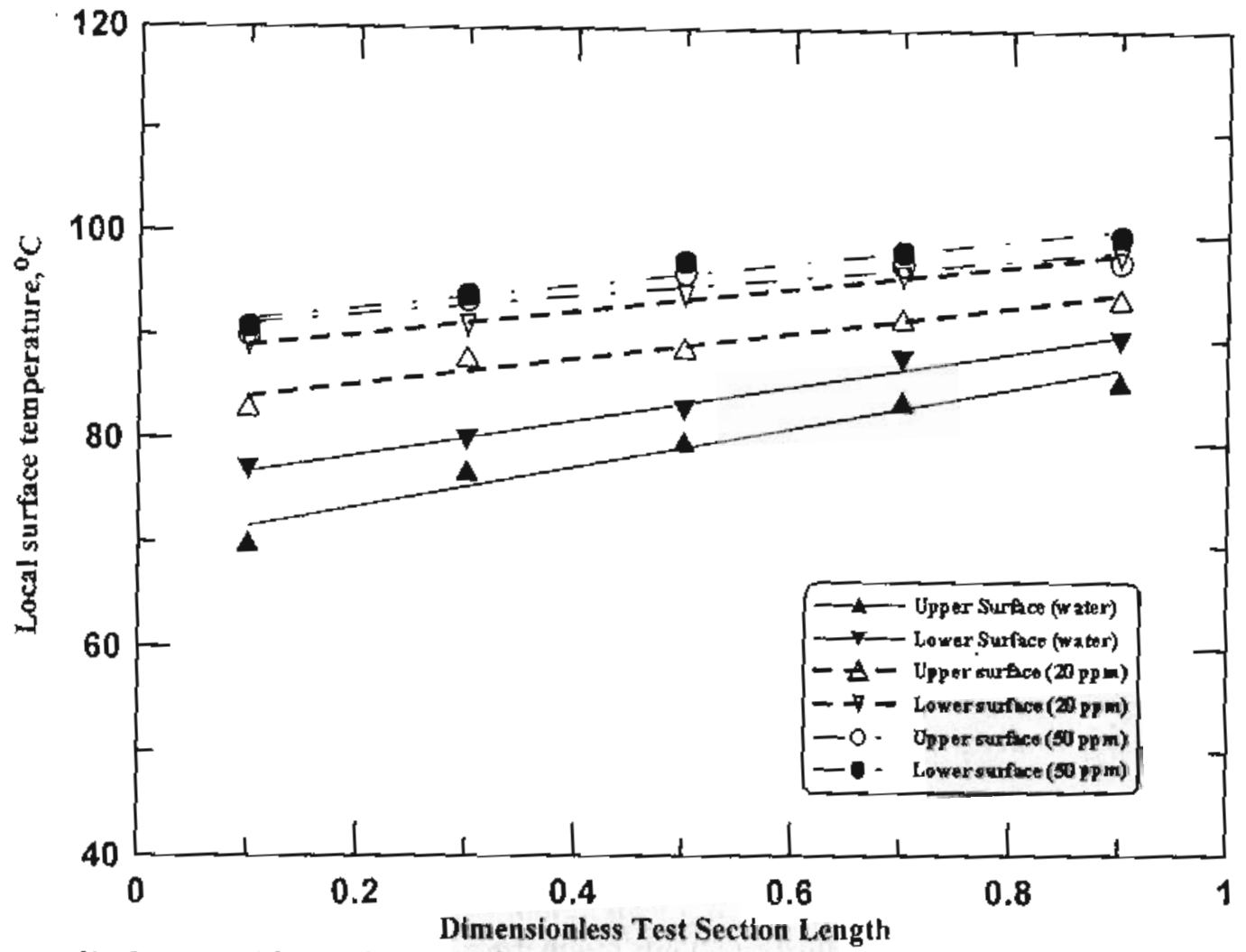

Figure(8) Upper and lower local surface temperatures versus dimensionless test section length for polymer solution with concentration ratios $(20 \mathrm{ppm}, 50 \mathrm{ppm})$ compared with water, $\operatorname{Re}=840$.

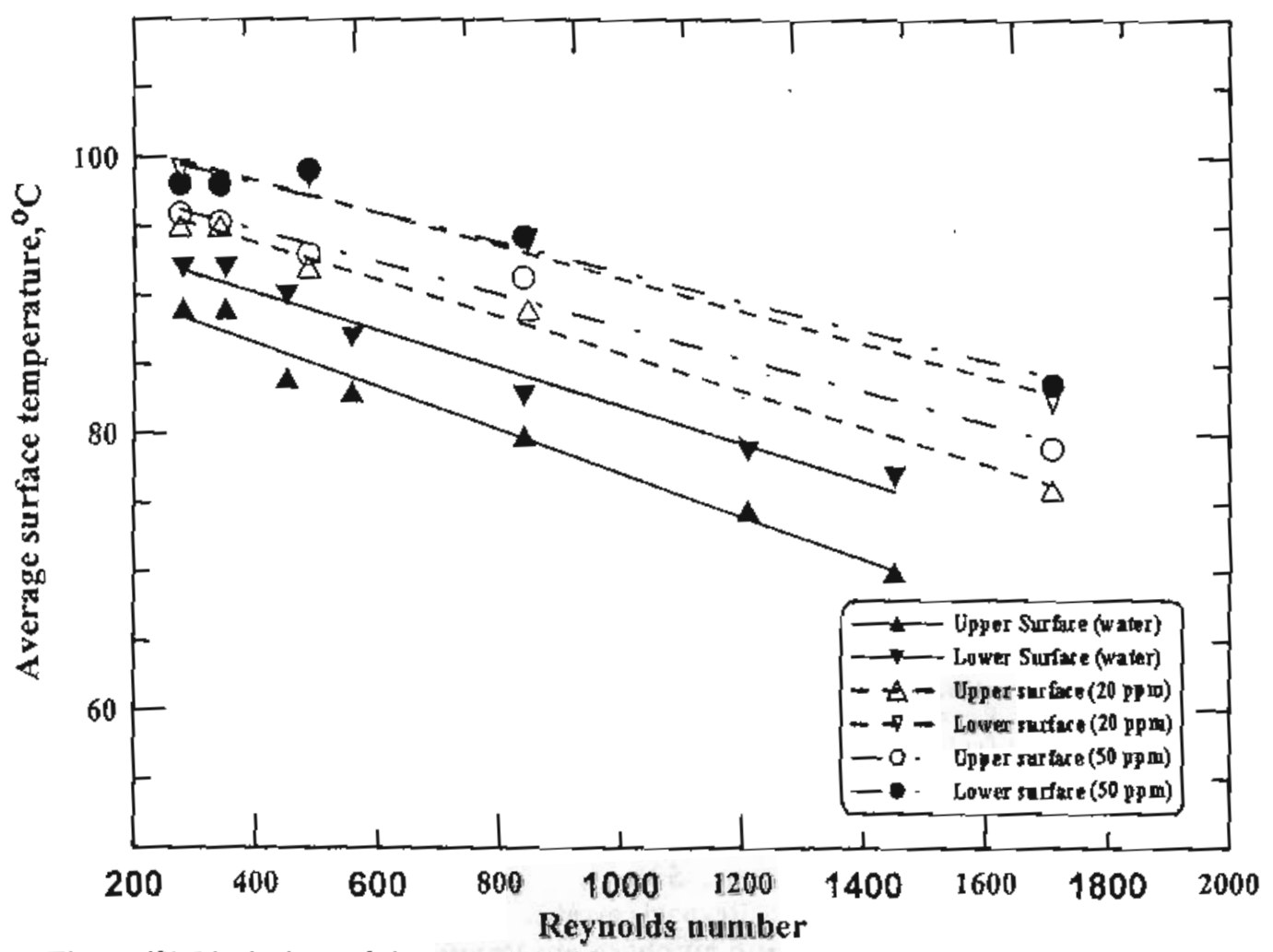

Figure(9) Variation of the upper and lower average surface temperatures versus Reynolds number for polymer solution with concentration ratios (20 ppm, $50 \mathrm{ppm}$ ) compared with water, $\operatorname{Re}=840$. 
M. 43 Hesham M. Mostafa and Tarek F. Oda

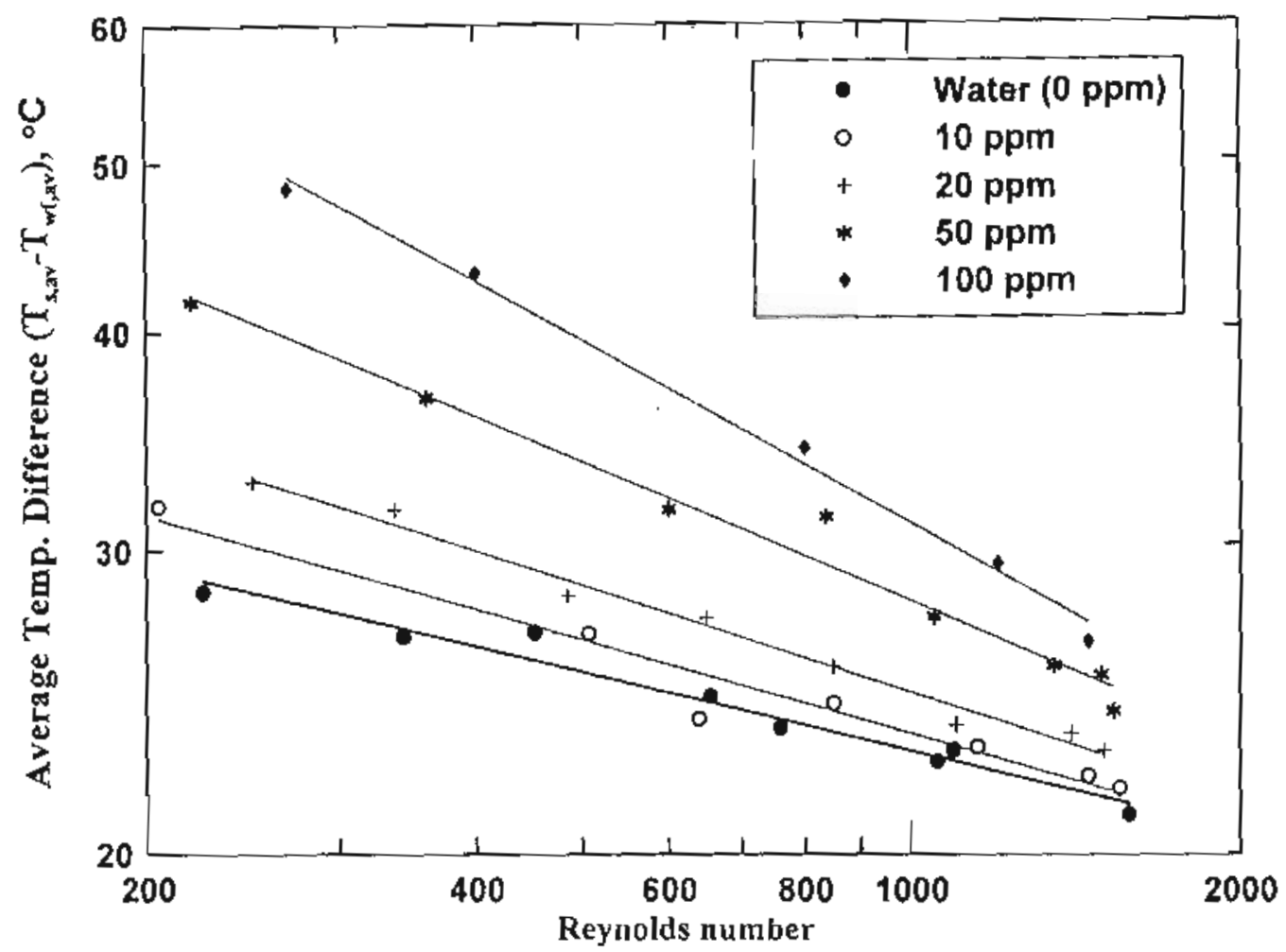

Figure (10) The variation of average temperature difference versus Reynolds number for polymer solutions compared with water.

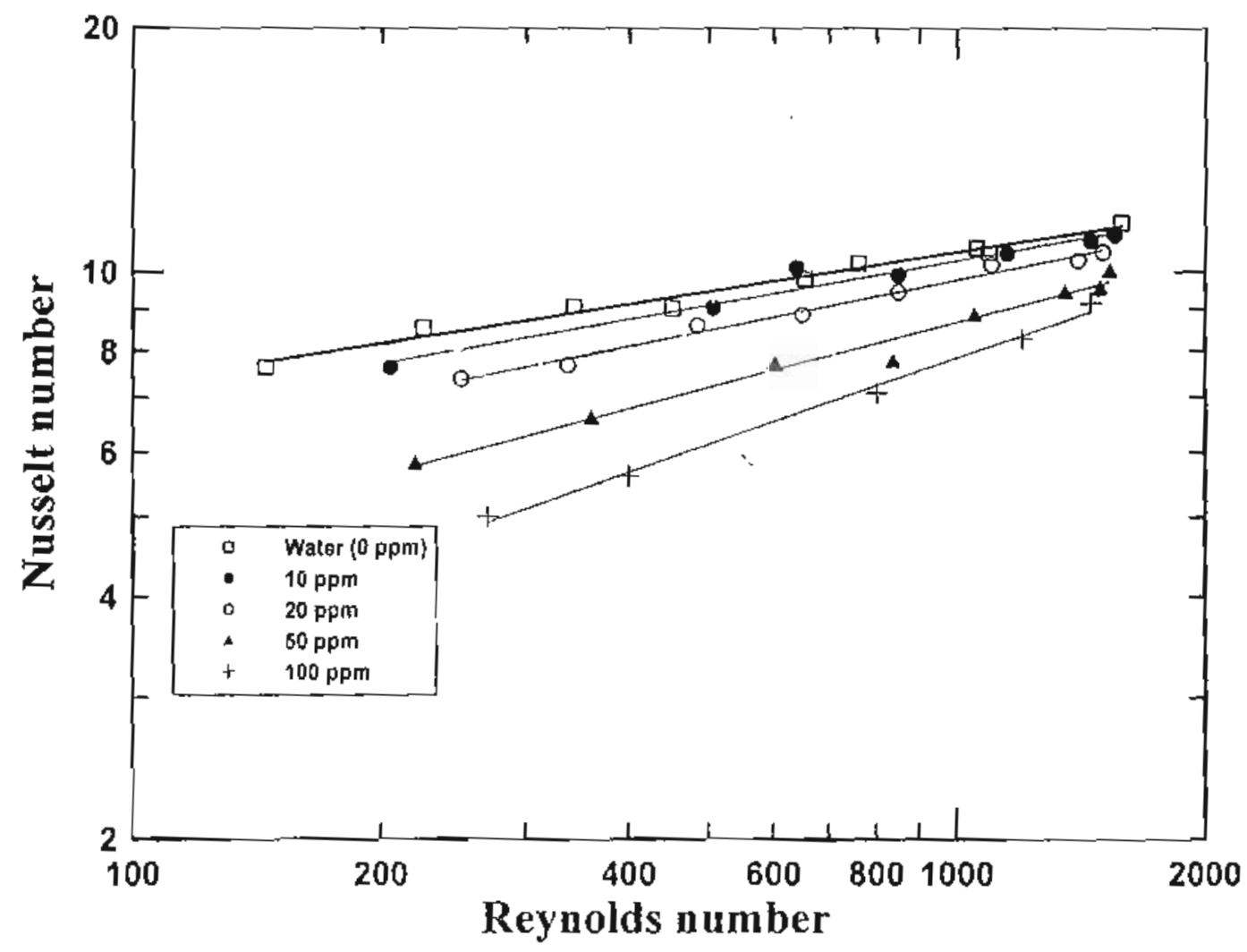

Figure (11) The variation of Nusslet number versus Reynofds number for polymer solutions compared with water. 


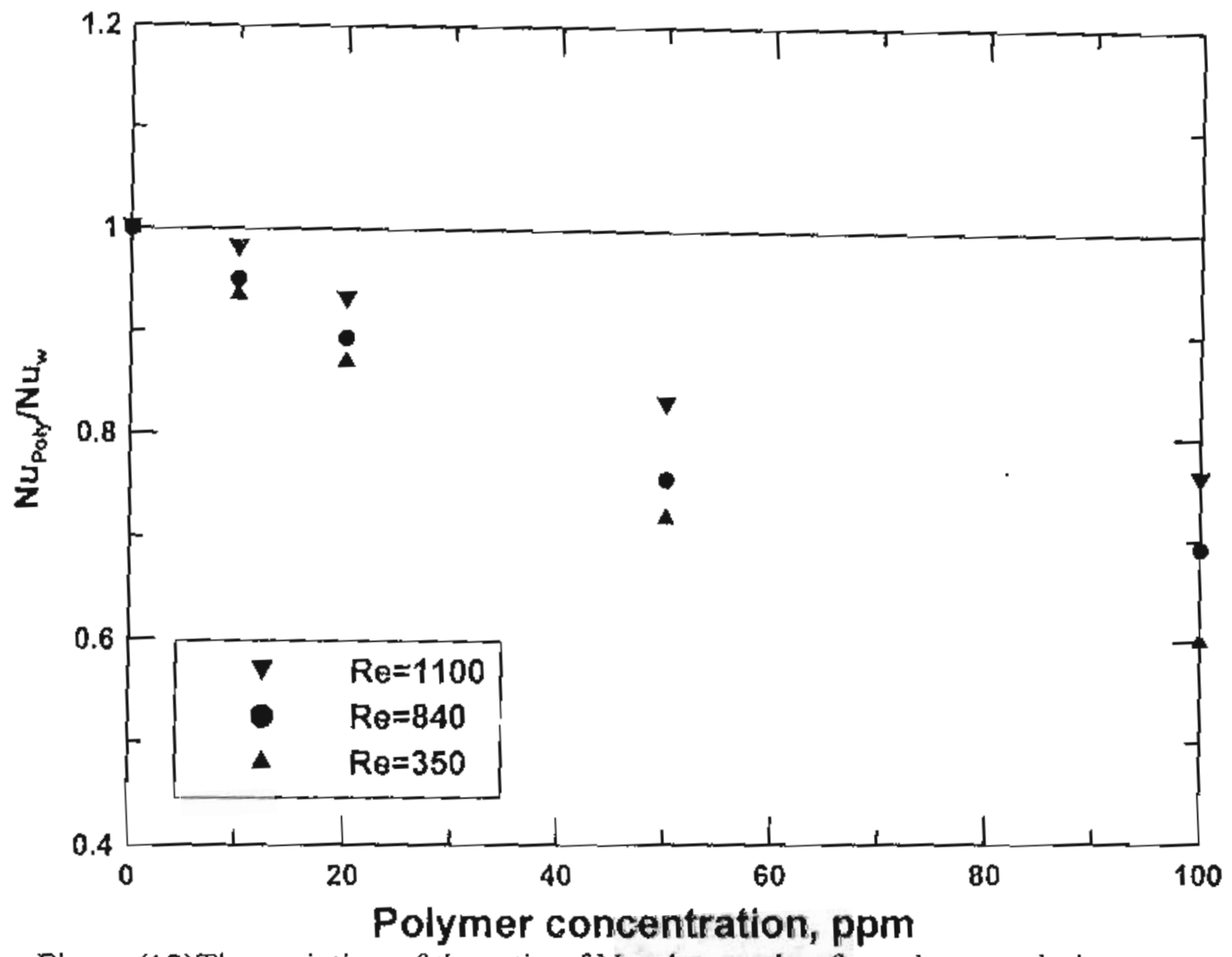

Figure (12)The variation of the ratio of Nusslet number for polymer solution over Nusslet number for water flow versus polymer concentrations.

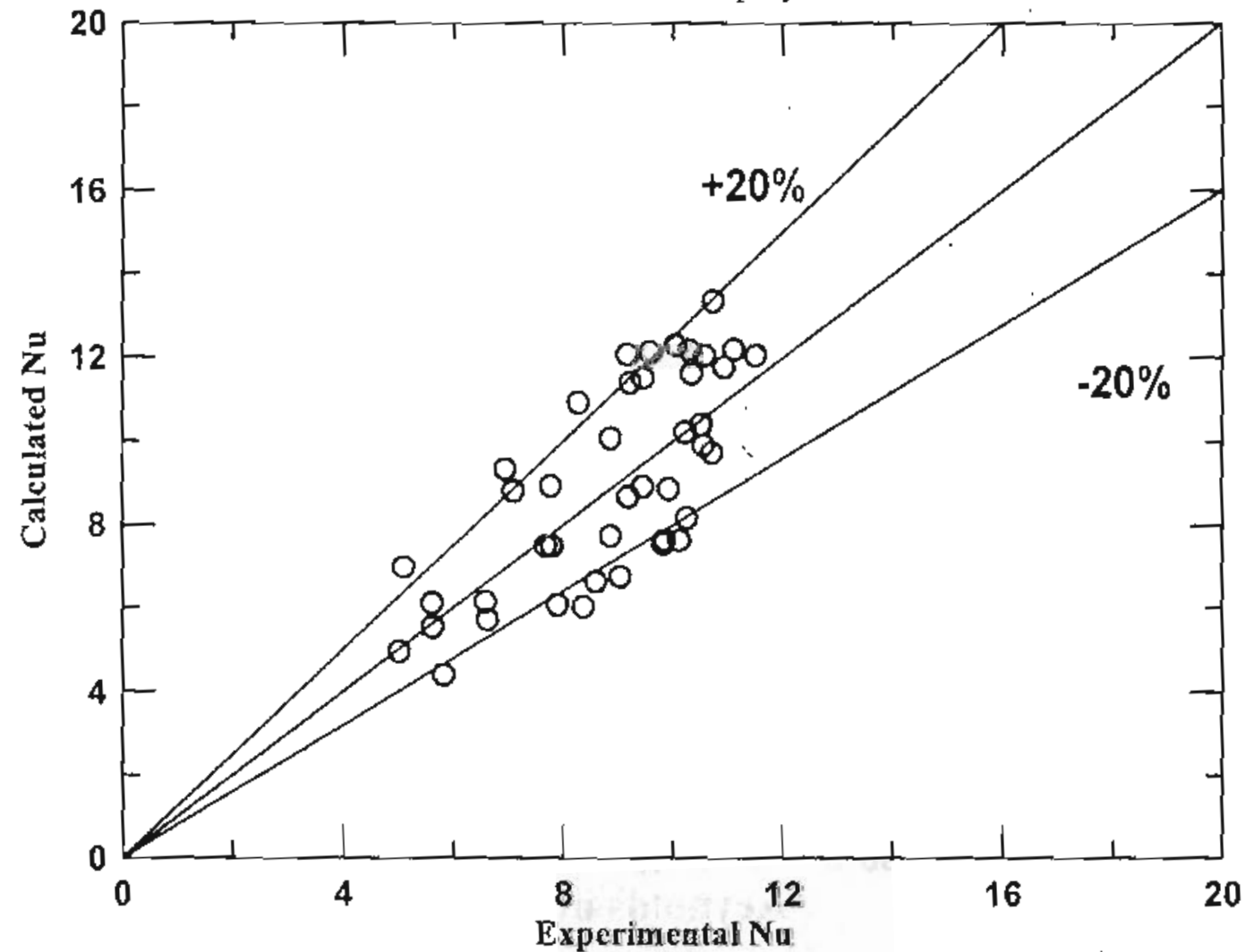

Figure (13) The deviation between Nusslet number evaluated from the experimental findings and the calculated Nusslet number from the present work correlation. 